\title{
Language as a Tool for Multinational companies, Insights on the Issue, including Albanian Market Proposal for Research
}

\author{
By ${ }^{1}$ MBA. Olda Çiço, ${ }^{2}$ Msc. Elfrida Dishmema, \\ ${ }^{3}$ Associate Professor Edmond Kadiu
}

\begin{abstract}
We communicate with words. Language as a tool of understanding, giving responses, making decisions, and having a better way to reach business goals is to be under consideration. This paper aims to explain why globalization has a very important impact on management, particularly because of the language used during various work aspects of multinational companies. The focus is why experience in this kind of research suggests writing on this issue and trying to implement the past results in Albania. While Albania is facing the integration process and it is part of a globalized economy, it has to be considered the fact that we are expecting more foreign investments, even from multinational companies. Cross-cultural problems are to be taken under consideration, especially the language.
\end{abstract}

Keywords: Language, knowledge, Diversity, Multinational Companies, Albania, Performance.

\section{Introduction}

The process of decision-making characterizes the day-to-day activities of multinational companies. Such decision-making activities encompass major strategic positioning like internationalization, new market entries, diversification or/and acquisitions. In most companies, strategic decisions are extensively discussed and debated. They are framed, formulated, articulated in the language often developed by the best minds in the company. Yet the language used in detailing and enacting the implementation strategy is usually taken for granted and receives little if any explicit attention (Brannen \& Doz, 2012). Multinational companies have come to recognize the importance of language when it comes to national language in deciding upon language policies and employing the services of specialized interpreters. This is all in order to avoid communication inefficiencies. They have also understood the importance of an official corporate language in regards to employees and investors commitment. The indicators of this are likely: carefully "word-smithed" statements of intentions and corporate values in annual reports, internal organizational documents and pocket - sized value-statement cards. In addition, more companies have begun to put in place language guidelines for use in virtual communication including e-mail, texting and video - 
conferencing in order to avoid misinterpretations. So, the interplay between corporate language and natural and national languages is a critical challenge to international business theory and practice (Welch, Welch, \& Piekkari, 2005). The common corporate language is built over time around firm-specific usages of words, acronyms, and stories that often reflect the industry context and the language environment in the firm's country of origin. While the corporate language is clear to insiders of the multinational companies, it is not to outsiders who lack this experience. Language is an artifact of how thoughts are formulated as well as how they are communicated and discussed. Therefore, the language used by decision makers in international business both shapes and bounds what the firm focuses on and how it articulates its strategic options (Brannen \& Doz, 2012). In this regard, language can facilitate and significantly limit strategic growth and performance of the multinational companies. It can review and decide the role of marketing decisions and their implementation.

Models about the internationalization process of the firm, both traditional (Johanson \& Vahlne, 1977; Luostarinen, 1979) and recent ones (Knight \& Cavusgil, 2004), are cases in point. Johanson and Wiedersheim-Paul (1975) viewed language as one of the key factors that prevented information about the target market from reaching organizational decision makers. More recently, there have been efforts to raise the field's awareness about the existence and influence of languages in internationally operating companies. This field of research remains unsophisticated in appreciating the multiple forms and features of language and its impact on multinational companies and on the way in which the phenomena is about to be studied. As such, we are about to seek insights gained from fields such as social communications, linguistics, anthropology, psychology, sociology, in order to generate some frames of reference for understanding the role of language in international business and marketing.

\section{Language and Knowledge}

During past decades, in some studies, people have devoted considerable attention to studying knowledge and knowledge transfer across cultural and geographical boundaries of multinational companies. But language considerations have remained a little peripheral in this endeavor. Nowadays, language and knowledge are seen as inseparably linked, because knowledge is always coded into language. This is especially true for firms operating in global contexts as strategy implementation is mediated by the effects of divergent cultural and institutional environments (Westney, 1993). Having employees and managers from different origins can provide tremendous opportunities for comparative learning for firms capable of simultaneously managing the additional demands from foreign markets, conflicting pressures on organizing issues in diverse cultural and institutional contexts, including the integration. We acknowledge the diversity of disciplinary perspectives on language and knowledge. For example, in linguistic anthropology language is considered as "a cultural resource" that (re)produces the social world (Duranti, 1997). Building on this, Tietze, Cohen and Musson (2003) define language as a system of meanings that is central in constructing organizational, social, and global realities. In this vein, language has a performative aspect because using language then becomes equivalent to "acting in the world." Language is the first and foremost means and source through which the connecting of different socio-cultural, institutional and individual worlds occurs (Tietze, 2008). Achieving such connections in 
international contexts is far from easy. Even in situations in which English is used as the common language, speakers attach invisible meanings to knowledge that stem from their own interpretive frames and complicate the transfer (Henderson Kassis, 2005). It is also to be considered the importance of verbal and non-verbal language in international business and marketing research. For example, in semiotic terms transferring the linguistic signals alone across borders does not ensure that the meaning is transferred as intended. On the contrary, more often than not shifts in meaning occur as the linguistic codes are given sense in a new cultural context, from the perspective of local interpretive frames and communicative norms (Brannen, 2004).

\section{Why is Language so important to International Business and Marketing Enquiry?}

We know the dominance of English as a lingua franca. On the contrary, given the growing importance of some countries' economies, languages such as Chinese, Russian, and Spanish are taking place. In this regard, this field has not advanced further in documenting and thus realizing the mechanisms by which multinational companies can learn from their operations in different language environments. One reason for this is that the methodologies used have been ineffective. In a special issue on qualitative research in International Business (Birkinshaw, Brannen, \& Tung, 2011), Westney and Van Maanen (2011) posit that this shortcoming is due to the fact that management knowledge in international business has been largely developed using classical economic models and that even when field-based studies have been deployed, these have been focused on executive-level practices. This has resulted in a "bird's-eye-view" from afar and atop rather than an "up-close" and contextually grounded understanding of the micro-processes that either block or facilitate the dynamic organizational learning that is essential for a multinational company to improve its performance. The latter requires research methodologies designed to surface deep, contextually rich insights from individuals at all levels, functions, and geographies in the multinational companies' multilingual community (Marschan-Piekkari, Welch, \& Welch, 1999).

Another reason for not realizing the mechanisms for organizational learning is that such learning is generally facilitated by multicultural teams. And, language, as both an essential artifact of culture and the vehicle by which strategic thoughts are formulated, communicated and discussed plays an essential role in the functioning of such teams. Building an integrated global strategy across markets which are geographically remote and have differing native languages and cultures is undoubtedly harder than what has been commonly acknowledged in international business research. Whether we are talking about language as the vehicle for expressing corporate strategic values and purpose (Brannen \& Doz, 2012) or languages as the means of expression of multiple unique cultures and groups within and around organizations (Harzing \& Feeley, 2008; Welch, 2005), the international business literature to date fails to take adequate account of its influence and impact on realizing international business goals.

\section{The meaning and value of this issue}

This special issue invites developing, discussing, or applying interdisciplinary language-based approaches to the mentioned phenomena in order to advance theory and 
research. We hope the issue to lead to an important reexamination of current models on international business and marketing, also frameworks and micro-processes through which multinational companies, institutions, and networks created. For example, themes may include understanding the effects of language on knowledge-sharing in multinational companies or how knowledge residing in foreign subsidiaries is managed in linguistically environments and origins. Challenges in regards to transferring explicit knowledge such as issues related to effectively translating standard operating procedures, processes, and polices as well as in transferring knowledge that is deeply socialized and context specific are of interest. Language considerations may also be one of the decisive factors in selecting an appropriate foreign operation mode to serve a target market or in making decisions about where to locate a shared service center or a foreign production unit. For marketing and service companies, resources in the customer language - both internal and external - may be instrumental in reaching out for foreign markets and providing highquality services. In terms of staffing and international human resource management, language requirements may influence job performance and affect staff selection, opportunities for promotion, as well as training and development. Bilingualism and multilingualism in global teams, cross-cultural communication, and innovation offer an increasingly relevant area of research. Given the internationalization process, it might be a relevant point of view for investors. So they would know how to spend their money best.

This special issue also invites to treat language as a methodological question and a window into cultural meanings. While researchers often construct survey instruments in multiple languages and pay considerable attention to equivalence of meaning and back translation (Usunier, 2011), the effect of the chosen language on survey responses is seldom examined. Language can act as a type of psychological fact that then affects survey responses. Further, data are generally collected and analyzed in one or multiple languages but reported predominantly in English. Such translations and crossing of language boundaries often go un-mentioned in methodology sections of published articles and therefore do not enter methodological debates. Further, this would be a matter to discuss and another issue to take under consideration. Discussions and experiences that contribute to the field by offering linguistic approaches are also to be heard. These approaches could be derived from evolutionary linguistics and sociolinguistics, as well as from other non-linguistically based fields such as political sciences, psychology, or even artificial intelligence in order to bring to the light tools such as translation, intercultural communication, negotiation, as well as micro aspects of managing multinational companies. Here, master degrees' students and $\mathrm{PhD}$ candidates may have their intellectual efforts by giving a thought and giving a hand to language perspective.

\section{How to invest and make interesting themes in this issue, including Albania case}

The purpose is, therefore, to identify new research questions that originate from a focus on language. Learning from published papers that approach established international business and marketing phenomena focused on language matters, and suggested contributions of interdisciplinary studies, the call is how to contribute to this issue in Albania. This invites language-sensitive research that is pluralistic in terms of underlying philosophical assumptions and research methods employed (Welch et al., 
2011). The purpose is to include theoretical and conceptual contributions as well as empirical work that draw on qualitative or quantitative methods or an innovative mix of both. To achieve this goal, conceptual pieces that attempt to frame language issues in multinational companies that operate in Albania are encouraged to be related to the following themes:

\section{Control, coordination, and communication in international organizations}

- In what ways does language use (corporate established language or national language use) affect communication and coordination within the company?

- How do national languages blend with corporate language?

- Is it meaningful having official language policies in subsidiaries or/and branches?

- How should they be designed and implemented?

- How do language policies and practices differ between different origins of multinational companies?

- How does language effect on organizational growth and performance?

- What are the costs associated with managing language diversity?

- Is there a need to re-examine the basic code-model of cross-cultural communication given today's changing workforce demographically or/and multicultural?

- What is the role and impact of non-verbal aspects of language on managing subsidiaries or/and branches?

Internationalization and foreign operations

- How does language explain different processes and patterns?

- How does language influence the choice and implementation of foreign operations, for example mergers, acquisitions, new investments, doing joint ventures, outsourcing?

- Does language generate cooperation or generate conflict between companies and their subsidiaries or/and branches?

partners?

Managing employees in international organizations

- How does language diversity influence workplace interactions and relationships between employees and their managers?

- Does language competence in particular pre-dispose managers to communicate better across cultural boundaries?

have on staff?

- What is the impact of a common corporate language on human resources policies and practices?

- How are language considerations taken into account when recruiting and effectively managing workers? environment?

How does the language related matters differ if employees work in a digital Innovation management, knowledge transfer, and organizational learning

How do language barriers enter global innovation and diversification processes? 
- What kind of new product or service innovations may emerge from multilingual global teams?

- How are language issues overcoming knowledge sharing and organizational learning across contexts?

- How is knowledge transfer in the absence of a common language?

International marketing issues

- How is translation handled in international marketing activities?

- How does the consideration of the "customer language" affect international marketing?

- How is language diversity accounted for in services that are offered across language boundaries?

- $\quad$ Are global branding and advertising language-free or language-dependent?

- What is the role of language in the traditional dilemma of global standardization and local adaptation?

Methodological issues

- How can key questions in research design and methods be better understood from a language perspective?

- How can questions and researches be better understood from whom they are read?

How can this kind of researches improve business and marketing decisions?

\section{Conclusion}

Setting boundaries on language used in multinational companies is proved to be inefficient. Managing cultural diversity, including language issues within is a challenge for companies. It is considered a globalization aftermath and it is a matter for researches and researchers to take under consideration. The studies of two past decades show the corporate language is clear to insiders of the multinational companies and it is not to outsiders who lack this experience. All kind of documentation used in multinational companies are considered important and their value increases if the language used is appropriate for those who read.

To achieve the goals set, conceptual pieces that attempt to frame language issues in multinational companies that operate in Albania are encouraged to be related to themes like: Control, coordination, and communication in international organizations, Foreign operations, Human Recources Management, Innovation management, marketing issues. Also, it is an important fact to use methodological issues like key questions in research design to achieve appropriate results to be better understood from multinational companies operating in Albania. Multilingualism is also likely to have indirect, longrange benefits stemming from the development of employees better equipped to oversee international organizations. 


\section{References}

Brannen, M. Y. 2000. National Cultures, networks, and individual influence in a multinational management team. Academy of Management Journal, 43(2): 191-202.

Brannen, M. Y., \& Doz, Y. L. 2010. From a distance and detached to up close and personal: Bridging strategic and cross-cultural perspectives in international management research and practice. Scandinavian Journal of Management, 26: 236-247.

Doz, Y. L., Santos, J., \& Williamson, P. 2001. From global to metanational: How companies win in the knowledge economy. Boston, MA: Harvard Business School Press.

Duranti, A. 1997. Linguistic anthropology. Cambridge: Cambridge University Press.

Levitt, B., \& March, J. G. 1988. Organizational learning. Annual Review of Sociology, 14: 319-340.

Marschan-Piekkari, R., Welch, D. E., \& Welch, L. S. 1999. In the shadow: The impact of language on structure, power and communication in the multinational. International Business Review, 8(4): 421-440.

Tietze, S. 2008. International management and language. London: Routledge

Welch, D. E., Welch, L. S., \&Piekkari, R. 2005. Speaking in tongues: The importance of language in international management processes. International Studies of Management \& Organization, 35(1): $10-27$.

Steers, R.M., Sanchez-Runde, C.J., Nardon, L., 2010. Management Across Cultures Challenges and Strategies. Cambridge University Press, 199-232. 
